\title{
Decision-Level and Feature-Level Integration of Remote Sensing and Geospatial Big Data for Urban Land Use Mapping
}

\author{
Jiadi Yin ${ }^{1,2}$, Ping Fu ${ }^{1, *}$, Nicholas A. S. Hamm ${ }^{1}{ }^{1}$, Zhichao $\mathrm{Li}^{2}$, Nanshan You ${ }^{2,3}$, Yingli He ${ }^{2,3}$, \\ Ali Cheshmehzangi ${ }^{4}(\mathbb{C})$ and Jinwei Dong ${ }^{2}$ (I)
}

1 School of Geographical Sciences and Geospatial and Geohazards Research Group, Faculty of Science and Engineering, University of Nottingham Ningbo China, Ningbo 315100, China; Jiadi.Yin@nottingham.edu.cn (J.Y.); Nicholas.Hamm@nottingham.edu.cn (N.A.S.H.)

2 Key Laboratory of Land Surface Pattern and Simulation, Institute of Geographic Sciences and Natural Resources Research, Chinese Academy of Sciences, Beijing 100101, China; lizc@igsnrr.ac.cn (Z.L.); youns.18b@igsnrr.ac.cn (N.Y.); heyl.19b@igsnrr.ac.cn (Y.H.); dongjw@igsnrr.ac.cn (J.D.)

3 University of Chinese Academy of Sciences, Beijing 100049, China

4 Department of Architecture and Built Environment, University of Nottingham Ningbo China, Ningbo 315100, China; Ali.Cheshmehzangi@nottingham.edu.cn

* Correspondence: Ping.Fu@nottingham.edu.cn

check for updates

Citation: Yin, J.; Fu, P.; Hamm, N.A.S.; Li, Z.; You, N.; He, Y.; Cheshmehzangi, A.; Dong, J. Decision-Level and Feature-Level Integration of Remote Sensing and Geospatial Big Data for Urban Land Use Mapping. Remote Sens. 2021, 13, 1579. https://doi.org/10.3390/ rs13081579

Academic Editor: Jochen Hack

Received: 23 February 2021

Accepted: 15 April 2021

Published: 19 April 2021

Publisher's Note: MDPI stays neutral with regard to jurisdictional claims in published maps and institutional affiliations.

Copyright: (c) 2021 by the authors Licensee MDPI, Basel, Switzerland. This article is an open access article distributed under the terms and conditions of the Creative Commons Attribution (CC BY) license (https:/ / creativecommons.org/licenses/by/ $4.0 /)$.

\begin{abstract}
Information about urban land use is important for urban planning and sustainable development. The emergence of geospatial big data (GBD), increased the availability of remotely sensed (RS) data and the development of new methods for data integration to provide new opportunities for mapping types of urban land use. However, the modes of RS and GBD integration are diverse due to the differences in data, study areas, classifiers, etc. In this context, this study aims to summarize the main methods of data integration and evaluate them via a case study of urban land use mapping in Hangzhou, China. We first categorized the RS and GBD integration methods into decision-level integration (DI) and feature-level integration (FI) and analyzed their main differences by reviewing the existing literature. The two methods were then applied for mapping urban land use types in Hangzhou city, based on urban parcels derived from the OpenStreetMap (OSM) road network, $10 \mathrm{~m}$ Sentinel-2A images, and points of interest (POI). The corresponding classification results were validated quantitatively and qualitatively using the same testing dataset. Finally, we illustrated the advantages and disadvantages of both approaches via bibliographic evidence and quantitative analysis. The results showed that: (1) The visual comparison indicates a generally better performance of DI-based classification than FI-based classification; (2) DI-based urban land use mapping is easy to implement, while FI-based land use mapping enables the mixture of features; (3) DI-based and FI-based methods can be used together to improve urban land use mapping, as they have different performances when classifying different types of land use. This study provides an improved understanding of urban land use mapping in terms of the RS and GBD integration strategy.
\end{abstract}

Keywords: urban land use; remote sensing; geospatial big data; decision-level integration; featurelevel integration; Hangzhou

\section{Introduction}

China has undergone rapid urbanization since the early 1980s, shown as substantial urban expansion and dynamics in urban land use and structure [1]. The timely and accurate urban land use information is important for guiding urban planning and land use management [2]. Remote sensing (RS) techniques were widely used to update urban land use information over the past few decades, by referring to the differences in aspects of texture, spectrum, and context among urban land use categories [3,4]. However, due to the high similarity among urban land use categories in physical attributes, it is hard to identify 
the complexity and diversity of urban internal structures [5,6], especially in cities with highdensity populations and buildings, such as Hangzhou, Beijing, Shanghai, and Shenzhen [7]. Mixed-use land and shadows from high-rise buildings also pose great challenges for the RS data classification. Big data are defined partly by their large size and their characteristics, in particular their volume, variety, and velocity [8]. Much of this big data are geo-referenced, or can be geo-referenced, leading to geospatial big data (GBD). The emergence of GBD [9], such as mobile phone positioning data [10,11], points-of-interest (POI) [12], social media data [13-15], traffic trajectory data [16], and geotagged photographs [17-19], provides new opportunities to delineate human dimensions in an urban environment [20]. These multi-sourced data contain abundant human activity information, compensating for the lack of socioeconomic attributes of the RS data [21].

The integration of the space-based RS data and the time-based GBD can improve the existing urban land use maps by providing more detailed socioeconomic information and finer spatio-temporal resolution [22-24]. Promising progress was made on the applications of integrated RS and GBD on urban land use mapping at different scales and regions [25-29]. For example, Liu et al. [30] collected six features (spatial, texture, spatial envelope, rotationinvariant from RS images, Tencent real-time user density, and POI) to identify the urban land use type within each land use parcel. Jia et al. [31] classified RS data and mobile phone positioning data separately and then fused the two results by using a decision fusion strategy for categorizing urban land use. However, it is still challenging to integrate RS and GBD for urban land use mapping because of the modality gap (i.e., the differences in spatial data quality, technical format, and data structure) and heterogeneity in the data [32].

In this context, the main goal of this study is to propose the general framework by summarizing the RS and GBD integration approaches used in urban land use mapping and illustrate the advantages and disadvantages by applying them to map the urban land use situation in Hangzhou city, China. To our knowledge, this is the first study to summarize the existing efforts of integrating RS and GBD for urban land use mapping and analyzing their differences.

\section{Related Work of RS and GBD Integration Used in Urban Land Use Mapping}

Based on the literature review of previous studies, we categorize the various methods of RS and GBD integration used in urban land use mapping into decision-level integration (DI) and feature-level integration (FI) by considering the data integration modes (e.g., integration timing or integration method). A general framework is proposed, as shown in Figure 1, to demonstrate and differentiate the two approaches. Briefly, the main difference between DI-based and FI-based urban land use mapping is that DI combines the classification results of the RS and GBD, whereas FI integrates the features extracted from the RS and GBD for classification.

\subsection{DI-Based Urban Land Use Mapping}

The DI-based urban land use mapping processes the RS and GBD independently with different models and methods and combines the RS-based and GBD-based results for further generating the urban land use map. The DI-based method was first introduced by Chang et al. [33] and provides an efficient way for mapping urban land use in Kunming City by integrating POI data and Landsat images. Since then, a series of studies have followed that method. For example, Song et al. [34] further developed the method by fully exploring GBD (Weibo POI, Baidu POI) for more in-depth information and combining them with RS data (Landsat images, Gaofen). Tu et al. [35] fused landscape metrics (i.e., total class area, patch density, number of patches, and Shannon's diversity index) taken from RS and human activity metrics (i.e., the density of human activities in different functional zones) extracted from mobile phone positioning data for classifying urban functional zones by hierarchical clustering. Jia et al. [31] integrated RS-based urban land cover maps and GBD-based urban land use maps for mapping urban land use through decision fusion strategy (i.e., certain fusion rules for classifying different urban land use categories). Zhao 
et al. [28] generated land cover types by training RS images with the semantic elements derived from OpenStreetMap (OSM) data, then identified each building through semantic classification by using POI. Xu et al. [36] extracted geographic information from RS and functional distribution from GBD (Gaode POI), then combined them by assigning different weights for urban land use mapping in China. In the DI-based method, the RS and GBD features are calculated and processed separately, avoiding the feature conflicting issues. Furthermore, it has the advantage of easy implementation. In summary, the RS and GBD features reflecting disparate attributes and dimensions are processed through independent methods, then fused by certain models (e.g., cross-correlation, decision fusion strategy).

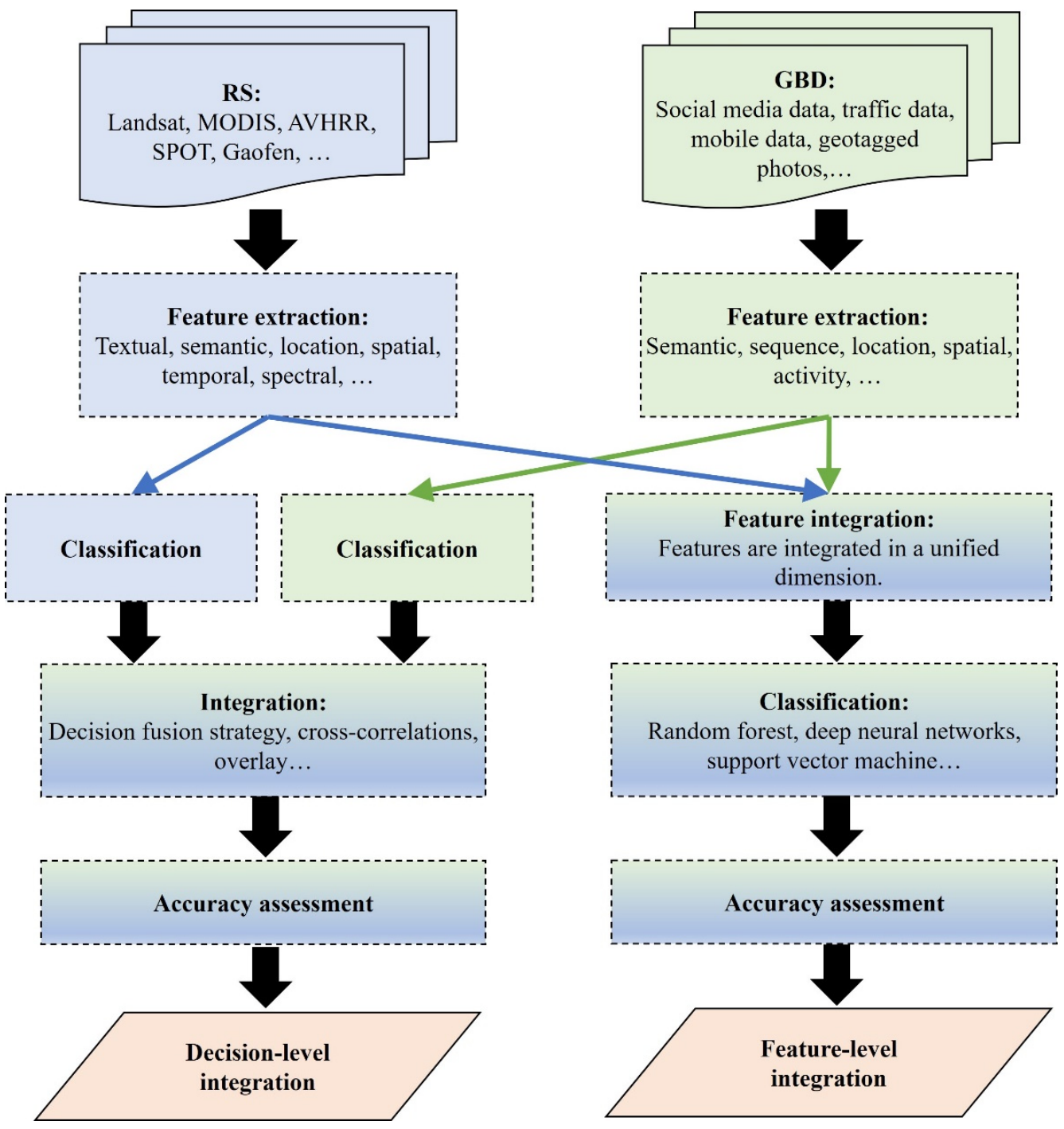

Figure 1. A general framework of the two integration strategies: Decision-level integration (DI), and Feature-level integration (FI).

\subsection{FI-Based Urban Land Use Mapping}

In the FI-based method, the features are first extracted from the RS and GBD and are then fused into the integrated feature sets and put into a classifier for urban land use classification. For example, Zhang et al. [37] extracted the features from the RS and GBD (i.e., spectral features, texture features, landscape metrics, density, spatial patterns of POI, and the density of geotagged Weibo posts), based on which urban land use types were determined and fused to train the classifiers for final mapping. Zhang et al. [27] evaluated the performances of the RS and GBD features and their cross-correlations for classifying urban functions by using a Random Forest (RF) model. Shi et al. [29] extracted 
RS features from ZY-3, Landsat8, Sentinel-1A, and GBD (e.g., Wechat user density) for identifying urban land use. Cao et al. [32] proposed a novel framework that extracted the RS-based and GBD-based features (e.g., temporal features from user-visit data) for recognizing urban land use through deep learning. Zhang et al. [25] extracted the RS and GBD features to construct a sparse topic model for identifying representative zones with distinct patterns, then trained these zones to recognize urban functional zones using the deep forest model. Compared to the DI-based approach, the FI-based approach provides a more integrative way of processing the features derived from both RS data and GBD. The RS-based and GBD-based features were fully used for the mining of the urban land use information. However, the modality gap (i.e., differences in data quality, data formats, scales, and timestamps between RS data and GBD) between the RS and GBD features is still a challenging issue.

\section{Case Study}

\subsection{Study Site}

Based on the general framework, a detailed methodological framework was designed for testing the two approaches (DI and FI) by using Hangzhou city as a case study. The case study was carried out in Hangzhou city, the capital of Zhejiang Province in China, which is one of the representative cities of urban expansion, population growth, economic development, and land use changes [38,39]. We selected the area surrounded by the third ring (i.e., the Hangzhou belt highway) as our study site, which is located in the northeast of Hangzhou city (Figure 2c). Besides, the green spaces in the West Lake ecological zone and the croplands in the northeast region were removed to ensure that our study site had the main functional areas related to urban human activities, including institutions, residences, businesses, and open space.
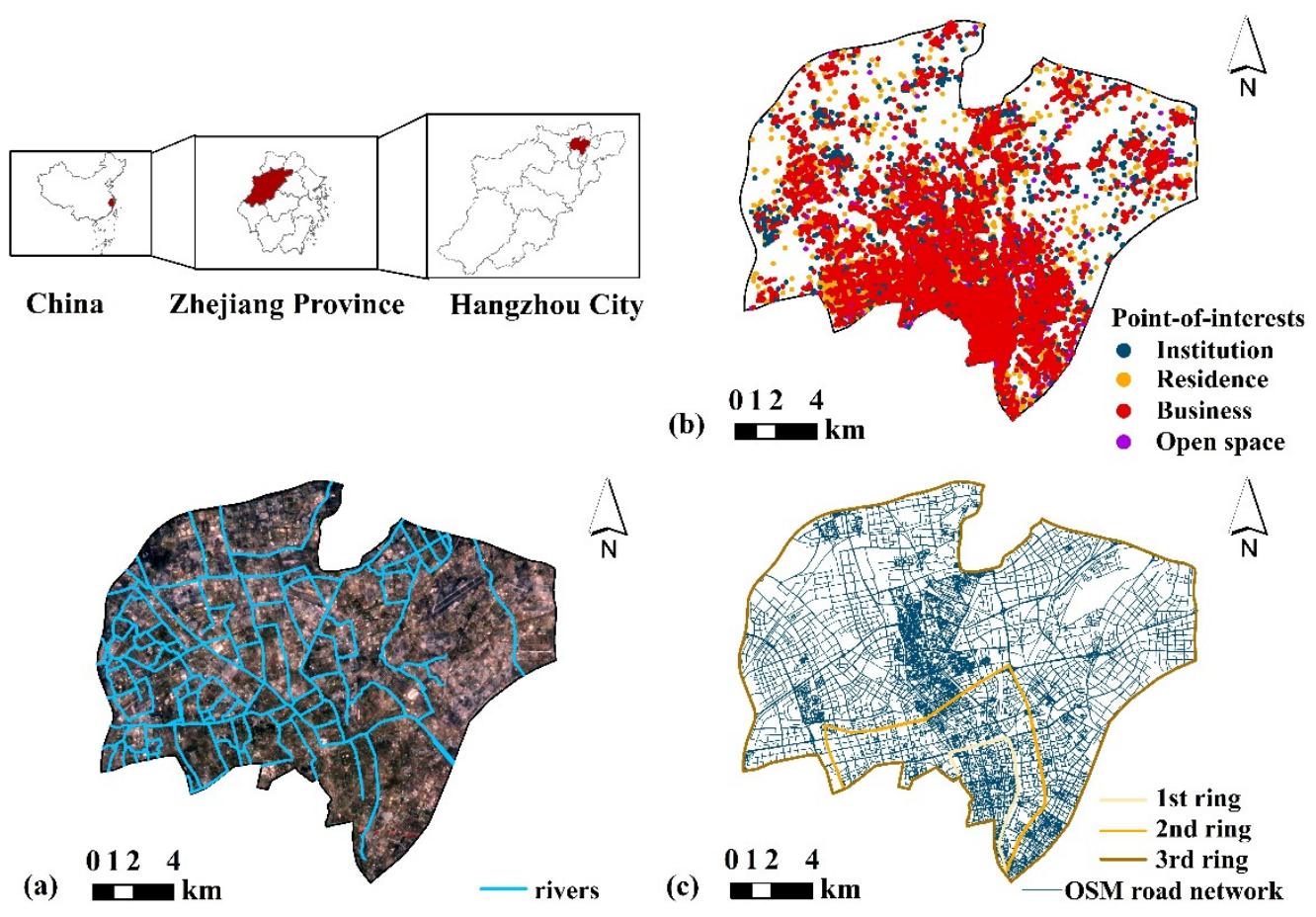

Figure 2. The study site (a) Sentinel-2 true-color composition image with OSM river network; (b) Spatial distribution of Point-of-interests (POI); (c) Road network extracted from OpenStreetMap (OSM). 


\subsection{Data Source and Preprocessing}

Sentinel-2 is a high-resolution $(10 \mathrm{~m})$, multi-spectral, remote-sensing satellite $[40,41]$. In this paper, the data were integrated from 1 January to 31 December 2019 as mean composites after removing clouds using the Sentinel-2 Quality Assurance (QA) band [42].

OpenStreetMap (OSM) is a collaborative project providing free editable maps across the world (https:/ / www.openstreetmap.org, accessed on 14 December 2019). The creation and growth of OSM data have mainly been promoted by users and GIS experts [43]. The high accuracy and free accessibility of OSM in urban areas have been confirmed by many researchers so far [44]. The weekly updated OSM data is very important for capturing the rapid development of urban areas. The OSM road network data are in vector format and contain different classes of roads with different road sizes $[45,46]$. It was proposed as a promising candidate for quick and robust delineations of urban structures and socioeconomic patterns since it is gradually being used to understand Chinese cities [47]. Thus, it is reliable to generate urban land use parcels using the OSM road network data.

As a prominent example of the GBD that attracts the most users, POI contain abundant information including land use category, geographic location, and other features (e.g., address, telephone, and postcode) [36]. A total number of 28,898 available records of POI within Hangzhou city in 2019 was collected via application programming interfaces (APIs) provided by Gaode Map Services. The urban land use classification system used for aggregating initial POI types were shown in Table 1 (https:/ / lbs.amap.com, accessed on 14 December 2019). Moreover, according to previous research, the urban area could be divided into six categories, including institution, residence, commercial land, industrial land, open space, and transportation $[25,36]$. Since we have excluded the road and river layers for generating urban parcels, there are five categories left. We further combined the commercial and industrial land into business as both have the nature of the business, and the business level meets the classification requirements of this paper. Therefore, the urban classification system used in this study consists of four categories: institution, residence, business, and open space.

Table 1. The framework used for aggregating initial Gaode POI types.

\begin{tabular}{|c|c|}
\hline Gaode POI Classification & Urban Land Use Classification \\
\hline $\begin{array}{l}\text { Governmental organization } \\
\text { Medical service } \\
\text { Finance and Insurance service } \\
\text { Sports and Recreation } \\
\text { Culture and Education }\end{array}$ & Institution \\
\hline $\begin{array}{l}\text { Daily life service } \\
\text { Commercial house }\end{array}$ & Residence \\
\hline $\begin{array}{l}\text { Commercial service } \\
\text { Shopping } \\
\text { Food and Beverages } \\
\text { Enterprises } \\
\text { Accommodation service }\end{array}$ & Business \\
\hline Tourist attraction & Open space \\
\hline
\end{tabular}

\subsection{Methods}

The case study was carried out with the assumption that a parcel divided by urban road networks is homogeneous in terms of urban land use function [44,48]. Quantitatively illustrating the differences between DI-based and FI-based methods requires the following steps: (1) extracting urban land parcels based on the road network and river data (Figure 3a) and preparing training and validation parcels (Figure $3 b$ ); (2) generating urban land use maps by using DI-based (Figure 3c) and FI-based methods, respectively, (Figure 3d) and evaluating the two based on validation datasets; (3) analyzing the differences between the 
two methods in terms of quantitative and qualitative assessment of resulting maps and their data processing modes. The detailed procedures are presented below.

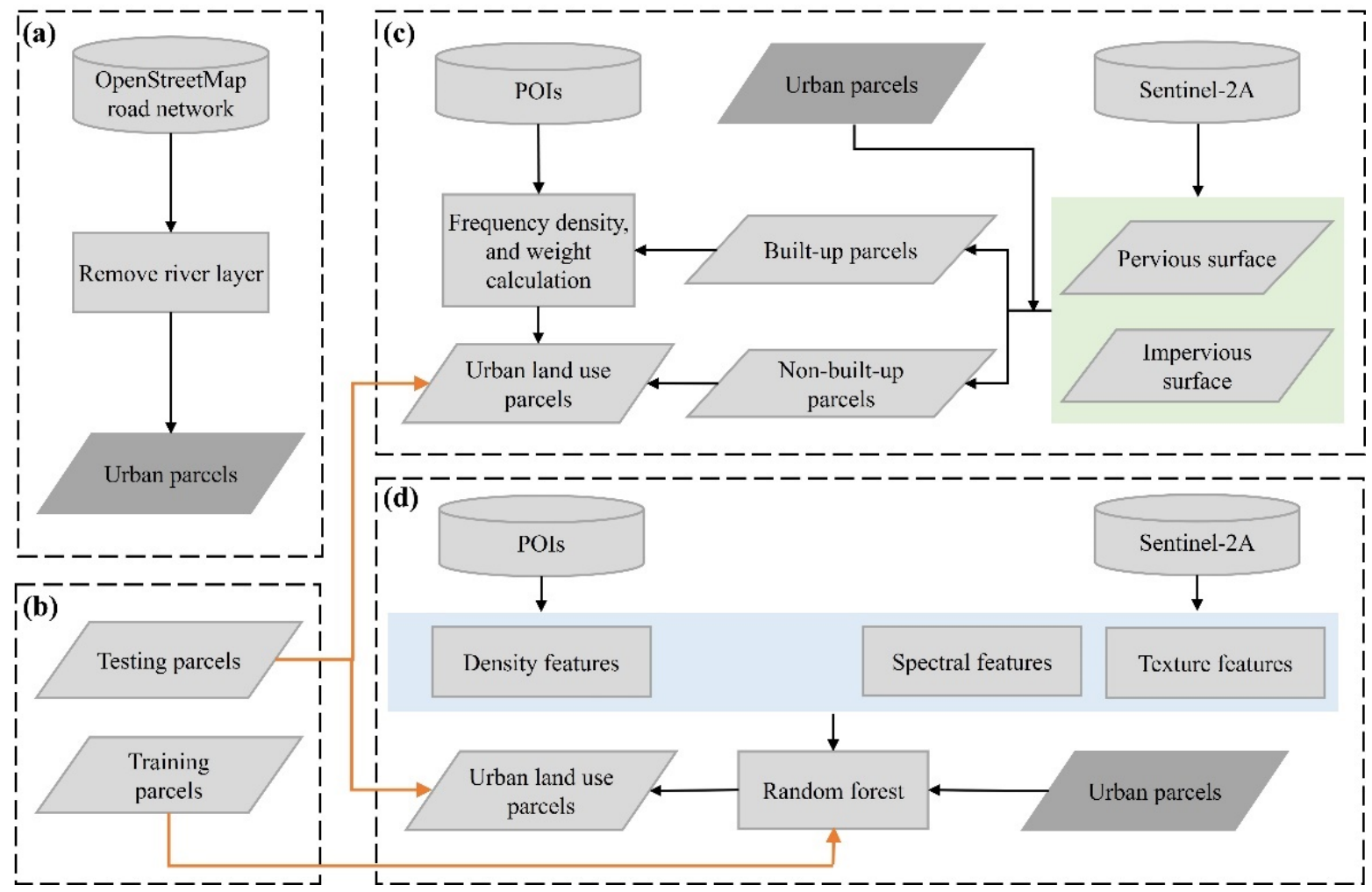

Figure 3. This is a figure. Schemes follow the same formatting. Research methodological framework of mapping urban land use with decision-level integration (DI) and feature-level integration (FI). (a) Urban parcel generation based on the road network and river data; (b) Collection of testing and training parcels; (c) DI-based urban land use mapping (DI); (d) FI-based urban land use mapping.

\subsubsection{Urban Parcel Generation}

The study area was segmented into urban parcels based on the method of the automated identification and characterization of parcels (AICP) [47]. Specifically, roads less than $100 \mathrm{~m}$ and roads inside communities were considered as redundant information and manually removed. The road network and river layer were then used for generating road buffers and river buffers. The buffer widths of the road and river were determined based on their respective classes according to the Ministry of Housing and Urban-Rural Development (MoHURD) [49] and the actual situation in Hangzhou city (Table 2). The river layer was delineated by visual interpretation based on Google Earth, and the preprocessing of the road network and buffer generation were conducted by using ArcMap 10.2.

Table 2. The road and river levels and their corresponding buffer sizes used in this study.

\begin{tabular}{ccccc}
\hline Classes & Road Descriptions & $\begin{array}{c}\text { Road } \\
\text { Widths (m) }\end{array}$ & River Descriptions & $\begin{array}{c}\text { River } \\
\text { Widths (m) }\end{array}$ \\
\hline Level 1 & $\begin{array}{c}\text { Trunk, primary, } \\
\text { motorway, railway } \\
\text { Level 2 }\end{array}$ & 40 & Main rivers & 50 \\
Level 3 & $\begin{array}{c}\text { Tertiary, unclassified, } \\
\text { residential, service, others }\end{array}$ & 10 & Intermediate rivers & 20 \\
\hline
\end{tabular}




\subsubsection{Training and Testing Parcel Collection}

We selected parcels for preparing the training and testing parcels, of which the land use types were identified by using the Baidu map, Baidu street view, and a field survey (Figures 4 and 5). The hybrid satellite map of Baidu map presents a top view of the urban landscape with high-resolution satellite imagery and names of ground features, which were further inspected or confirmed using Baidu street view as it contains highresolution photos and allows multiple perspectives [50,51]. An example was presented in Figure 4 to illustrate the top view of an institution and residence in the Baidu map and their corresponding Baidu street views. We determined the parcel type while different types of street views were observed for the same parcel, and there is no predominant characteristic referring to the rules in essential urban land use categories in China (EULUC-China) [52]. To be more specific, we recorded a list of items, including the geolocations, classification types, landmark buildings and facilities, and mixed land use situation and their estimated proportions for each urban parcel. Finally, a total of 700 training parcels were identified, including 175 institution parcels, 175 residence parcels, 175 business parcels, and 175 open space parcels. These parcels were selected using stratified random sampling, with an equal sample size (175) for each land use class. Following the approach discussed by Stehmen and Foody [53], we selected 550 parcels for testing. These 550 parcels were selected using simple random sampling from the list of parcels. For each parcel, the land use class was determined by visual interpretation based on the Baidu map. The 550 parcels included 85 institution parcels, 225 residence parcels, 156 business parcels, and 84 open space parcels. The training parcels were used for training the RF classifiers in FI-based classification, while testing parcels were used for accuracy assessment in both DI-based and FI-based classification, respectively.
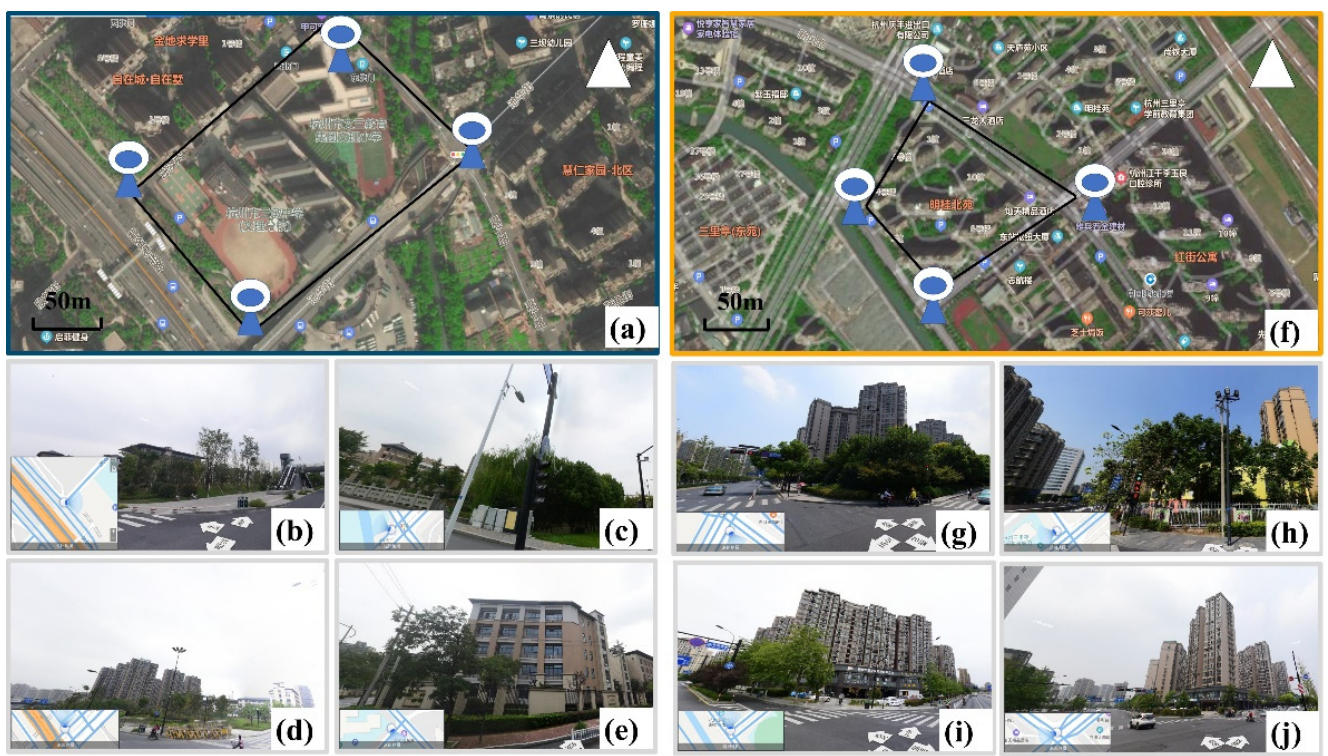

Figure 4. Illustration of the institution and residence parcels in Baidu map and Baidu street view: (a) represents the institution parcel in Baidu map; $(\mathbf{b}-\mathbf{e})$ represent the four perspectives of institution parcel in Baidu street view; (f) represents the residence parcel in Baidu map; and $(\mathbf{g}-\mathbf{j})$ represent the four perspectives of residence parcel in Baidu street view. The Chinese labels for $(\mathbf{a}, \mathbf{f})$ represent the name of POIs. 


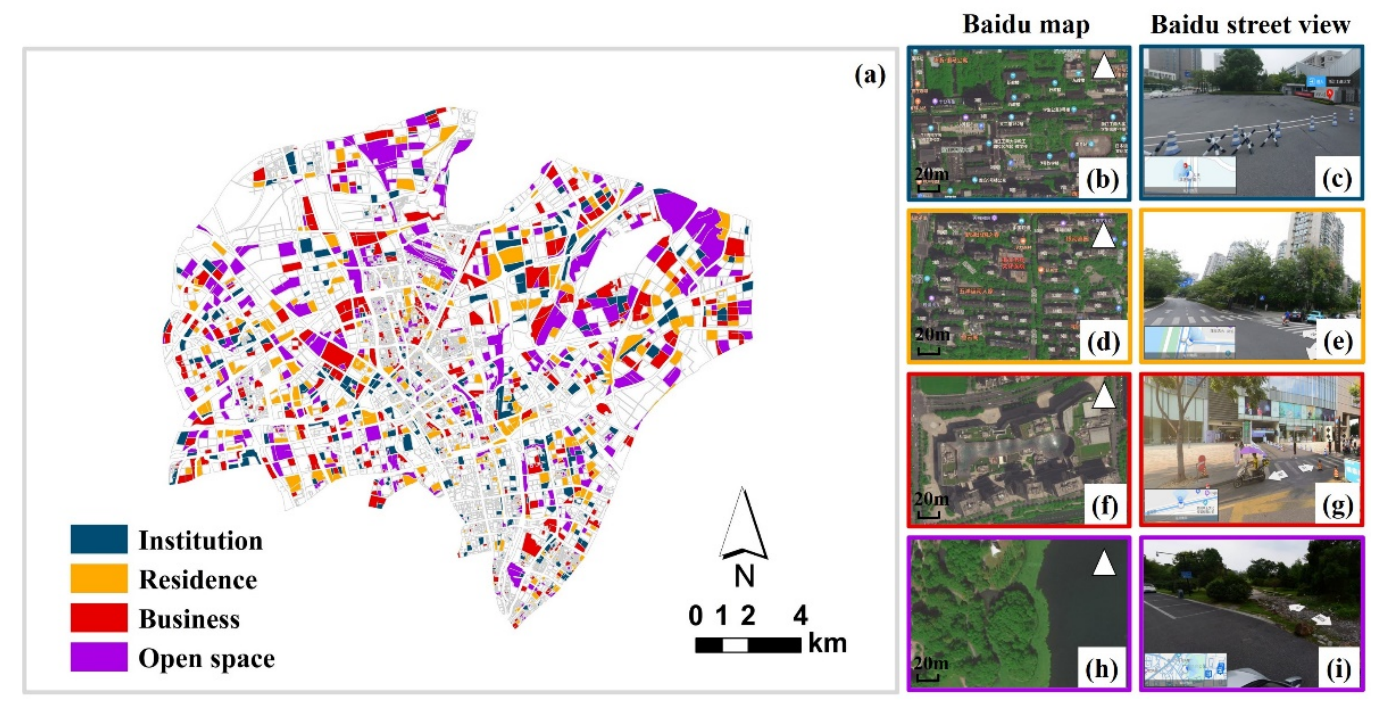

Figure 5. Spatial distribution and illustration of training and testing parcels for the four urban land use types. (a) represents the spatial distribution of training and testing parcels; $(\mathbf{b}, \mathbf{d}, \mathbf{f}, \mathbf{h})$ represents the Baidu map image for institution, residence, business, and open space, respectively; and (c,e,g,i) represent the Baidu street view for the institution, residence, business, and open space, respectively. The Chinese labels for $(\mathbf{b}, \mathbf{d}, \mathbf{f}, \mathbf{h})$ represent the name of POIs.

\subsubsection{DI-Based Urban Land Use Mapping}

The DI-based urban land use mapping integrated the results of the RS and GBD classification based on integration rules (Figure 3c). First, the Sentinel-2 image was classified for producing the impervious and pervious classes (Figure 6a). Specifically, the training samples identified by visual interpretation based on Google Earth and a field survey were put into the RF classifier for the classification of the impervious and pervious surface. The impervious surface is characterized by the artificial structures that are covered by waterresistant materials, while the pervious surface is the opposite [54]. The classification result was then overlaid with the urban parcels to generate the built-up and non-built-up parcels (Figure 6b). In this study, urban parcels with impervious surfaces were defined as built-up, otherwise, the parcels were labeled as non-built-up. This step was carried out under the assumption that built-up parcels require at least partially impervious surfaces [33]. The non-built-up parcels were further classified as open space, while built-up parcels were used for further analysis.

(a)

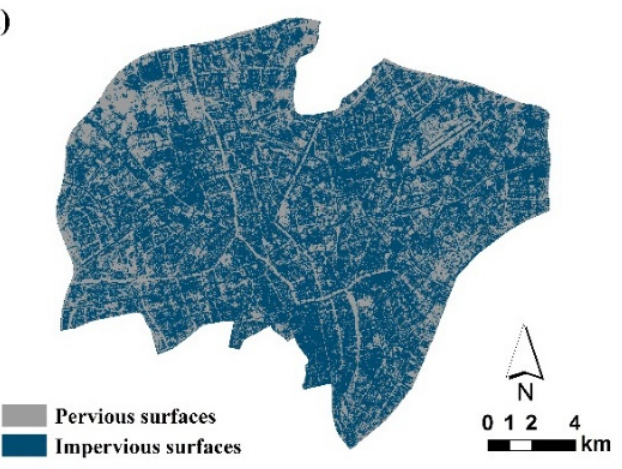

(b)

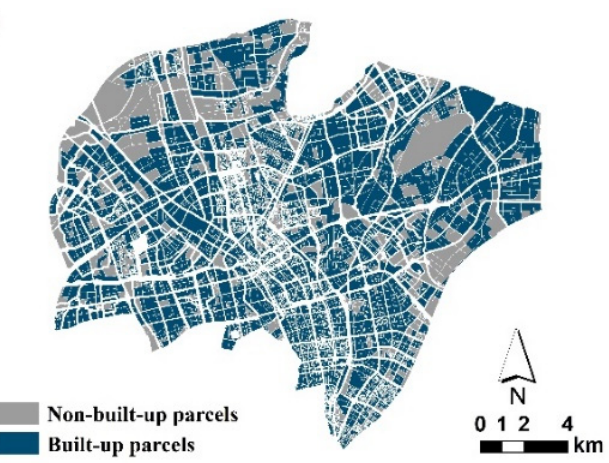

Figure 6. (a) Distribution of the pervious and impervious classes; (b) Distribution of the built-up and non-built-up parcels.

Finally, the type of each built-up parcel was determined according to a modified method [55]. The method consists of two parts: the frequency density calculation, and the weight calculation. In general, the main type in each parcel was determined after comparing the final frequency density ratios of four types of the POI, and the highest ratio of POI is considered as the final type. The final frequency density ratios were determined 
by multiplying the initial frequency density ratio and the weight of each types' POI. Specifically, the initial frequency density ratios of the four types' POI were calculated by using Equations (1)-(3).

$$
F_{i}=\frac{n_{i}}{N_{i}}, i=1,2,3,4
$$

where $i$ represents the type of POI, which are institution, residence, business, or open space. $n_{i}$ demonstrates the quantity of type $i$ in a parcel. $N_{i}$ represents the total quantity of type $i$ in all parcels. $F_{i}$ demonstrates the frequency density which equals the ratio of $n_{i}$ to $N_{i}$.

$$
C_{i}=\frac{F_{i}}{\sum_{1}^{4} F_{i}} \times 100 \%, i=1,2,3,4
$$

where $C_{i}$ represents the initial ratio of type $i$ 's frequency density to the sum of all four types' frequency density.

The initial frequency density ratios of the four types' POI were then respectively multiplied with their weights since various types of POI have different recognition degrees. The weight of institution, residence, business, and open space POI was defined as 2, 1, 1.5 , and 2.5 , referring to the construction area and the actual situation. The type in each parcel was determined as the one with the highest ratio and the final urban land use map was obtained. The open space parcels produced by the calculation of POI were further combined with the non-built-up parcels as the final open space parcels.

$$
D_{i}=C_{i} \times W_{i} \times 100 \%, i=1,2,3,4
$$

where $D_{i}$ represents the final frequency density ratio which equals the initial ratio of type $i$ 's frequency density multiplying the weight of each types' POI. $W_{1}=2, W_{2}=1, W_{3}=$ $1.5, W_{4}=2.5$.

\subsubsection{FI-Based Urban Land Use Mapping}

The FI-based classification used 18 features derived from the RS and GBD, including eight spectral features, four textural features, and six density features (Table 3). Textural features indicate the adjacency relationships between the gray levels of pixels to characterize the texture of an image $[37,56]$. In this study, the textural features (i.e., angular second moment, contrast, dissimilarity, and entropy) were extracted by computing Gray Level Co-Occurrence Matrix (GLCM) that contain rich information on spatial structure and landscapes [57]. The near-infrared (NIR) band from the Sentinel image was used for computing the spectral and textural features, as it contains a negative correlation between built-up and vegetation [58-60]. Moreover, density features from POI help to present the differences in spatial patterns among different types of parcels. The Kernel Density Estimation (KDE) tool in ArcMap 10.2 was utilized to generate four layers of kernel density of the four land use types of POI, respectively. In FI-based classification, the RF model was trained using all the above-mentioned features 100 times to attenuate the uncertainties and get more stable accuracies. All of the operations in the FI-based classification were realized using the Google Earth Engine (GEE) platform.

Table 3. Spectral and textural features from RS, and density features from GBD used in FI-based classification.

\begin{tabular}{cc}
\hline Feature Types & Indices \\
\hline Spectral features & Enhanced Vegetation Index (EVI), Normal Difference Built-up \\
& Index (NDBI), Normal Difference Vegetation Index (NDVI), \\
& Normal Difference Water Index (NDWI), mean, standard \\
dextural features & deviation, kurtosis, skewness \\
Density features & Angular second moment, contrast, dissimilarity, and entropy \\
Minimum, maximum, range, sum, mean and standard deviation
\end{tabular}




\subsubsection{Analysis of the DI-Based and FI-Based Classification}

To understand the differences between DI-based and FI-based urban land use mapping and describe their advantages and disadvantages, we first evaluated the results derived from the two methods by computing the overall accuracy (OA), user's accuracy (UA), and producer's accuracy (PA) based on the confusion matrix [61]. Approximately 95\% confidence intervals of OA, UA, and PA were also calculated based on the equations proposed by Card [62] (Supplementary Materials). In the estimation procedure for DI and FI methods, we used a proportion of the number of parcels in each category, relative to all categories in the DI and FI classification results, and denoted this as $w_{j}$, following Olofsson, et al. [63], and Stehmen and Foody [53]. The column refers to the classified map category while the row refers to the true category based on the reference data (see the Supplementary Materials). For DI, No Data parcels refer to the parcels without POI values that were not involved in the confusion matrix. We then implemented the visual analysis of the DI-based and FI-based urban land use maps. Furthermore, we evaluated the implementation of the two methods by discussing their advantages and disadvantages.

\section{Results}

\subsection{Quantitative Performance of DI-Based and FI-Based Urban Land Use Mapping}

Table 4 showed the confusion matrix of the pervious and impervious map. The estimated OA ( $\pm 95 \%$ confidence interval) is $0.971 \pm 0.007$. The estimated UA and PA of the impervious surface are $0.975 \pm 0.008$ and $0.986 \pm 0.005$. Table 5 presents the confusion matrix of DI-based classification. The estimated OA for DI-based urban land use map is $0.635 \pm 0.049$. Note that the residence and open space were classified relatively well, with the estimated UA of $0.728 \pm 0.069$ and $0.714 \pm 0.140$, respectively. For institution and business, they have relatively lower UA $(0.512 \pm 0.140$ and $0.522 \pm 0.095)$. Table 6 presents the confusion matrix of FI-based classification. The estimated OA for FI-based classification results is $0.569 \pm 0.041$ (Table 6). It can be noted that the residence and open space in FI-based classification can be classified relatively well, with the UA of $0.631 \pm 0.059$ and $0.640 \pm 0.111$, respectively.

Table 4. Confusion matrix of the impervious and pervious surface extraction results. UA: users accuracy; PA: producers accuracy; OA: overall accuracy; $\pi_{-} \mathrm{j}$ is the class proportion according to the classified map.

\begin{tabular}{ccccccc}
\hline & \multicolumn{9}{c}{ Map Category } & & & \\
\cline { 2 - 7 } & Class & Pervious & Impervious & Total & PA & OA \\
\hline \multirow{3}{*}{ True } & Pervious & 0.240 & 0.018 & 0.258 & $0.928 \pm 0.022$ & $0.971 \pm 0.007$ \\
Category & Impervious & 0.010 & 0.732 & 0.742 & $0.986 \pm 0.005$ & \\
& Total $\left(\pi_{j}\right)$ & 0.250 & 0.750 & 1.000 & & \\
\hline
\end{tabular}

Table 5. Confusion matrix of DI-based classification results (I: Institution; R: Residence; B: Business; O: Open Space). UA: users accuracy; PA: producers accuracy; $\mathrm{OA}$ : overall accuracy; $\pi_{-} \mathrm{j}$ is the class proportion according to the classified map.

\begin{tabular}{|c|c|c|c|c|c|c|c|c|}
\hline & \multicolumn{6}{|c|}{ Map Category } & \multirow[b]{2}{*}{ PA } & \multirow[b]{2}{*}{ OA } \\
\hline & Class & I & $\mathbf{R}$ & B & O & Total & & \\
\hline \multirow{6}{*}{$\begin{array}{c}\text { True } \\
\text { Category }\end{array}$} & I & 0.071 & 0.029 & 0.042 & 0.014 & 0.156 & $0.453 \pm 0.107$ & \multirow[t]{6}{*}{$0.635 \pm 0.049$} \\
\hline & $\mathrm{R}$ & 0.015 & 0.326 & 0.072 & 0.008 & 0.421 & $0.774 \pm 0.055$ & \\
\hline & B & 0.034 & 0.065 & 0.157 & 0.010 & 0.265 & $0.591 \pm 0.082$ & \\
\hline & $\mathrm{O}$ & 0.019 & 0.029 & 0.029 & 0.081 & 0.158 & $0.514 \pm 0.102$ & \\
\hline & $\operatorname{Total}\left(\pi_{j}\right)$ & 0.138 & 0.448 & 0.300 & 0.113 & 1.000 & & \\
\hline & UA & $0.512 \pm 0.140$ & $0.728 \pm 0.069$ & $0.522 \pm 0.095$ & $0.714 \pm 0.140$ & & & \\
\hline
\end{tabular}


Table 6. Confusion matrix of FI-based classification results (I: Institution; R: Residence; B: Business; O: Open Space). UA: users accuracy; PA: producers accuracy; OA: overall accuracy; $\pi_{-} j$ is the class proportion according to the classified map.

\begin{tabular}{ccccccccc}
\hline & \multicolumn{9}{c}{ Map Category } \\
\cline { 2 - 9 } & Class & I & R & B & O & Total & PA & OA \\
\hline True & I & 0.071 & 0.030 & 0.025 & 0.016 & 0.142 & $0.496 \pm 0.092$ & $0.569 \pm 0.041$ \\
Category & $\mathrm{R}$ & 0.020 & 0.291 & 0.108 & 0.019 & 0.439 & $0.663 \pm 0.045$ & \\
& $\mathrm{~B}$ & 0.036 & 0.112 & 0.124 & 0.012 & 0.284 & $0.436 \pm 0.062$ \\
& $\mathrm{O}$ & 0.008 & 0.028 & 0.015 & 0.084 & 0.135 & $0.620 \pm 0.094$ \\
& Total $\left(\pi_{j}\right)$ & 0.135 & 0.462 & 0.272 & 0.130 & 1.000 & & \\
\hline
\end{tabular}

\subsection{Qualitative Performance of DI-Based and FI-Based Urban Land Use Mapping}

Figure 7 presents the urban land use maps derived from DI-based and FI-based methods in Hangzhou city. Overall, there is a difference in the number of each urban land use type, and the spatial distribution of the four land use types is not similar. In the DI-based map, the residence parcels were mainly distributed in the city center, while the open space parcels were distributed around Hangzhou city. The distribution of urban land uses in the DI-based map was visually consistent with the actual urban land use referring to the Baidu map. In the FI-based resulting map, the distribution of each land use type was more widely spread out across the study area than that in the DI resulting map. No-value parcels only exist in the resultant map from the DI-based classification, where the built-up parcels determined from the RS images are further labeled based on POI (see Section 3.3.3). No-value parcels arise where there is no POI data within the built-up parcel to support this labeling. On the contrary, the FI-based classification integrates features from both RS and GBD before land use classification could be classified, as each parcel contains features at least from RS data.
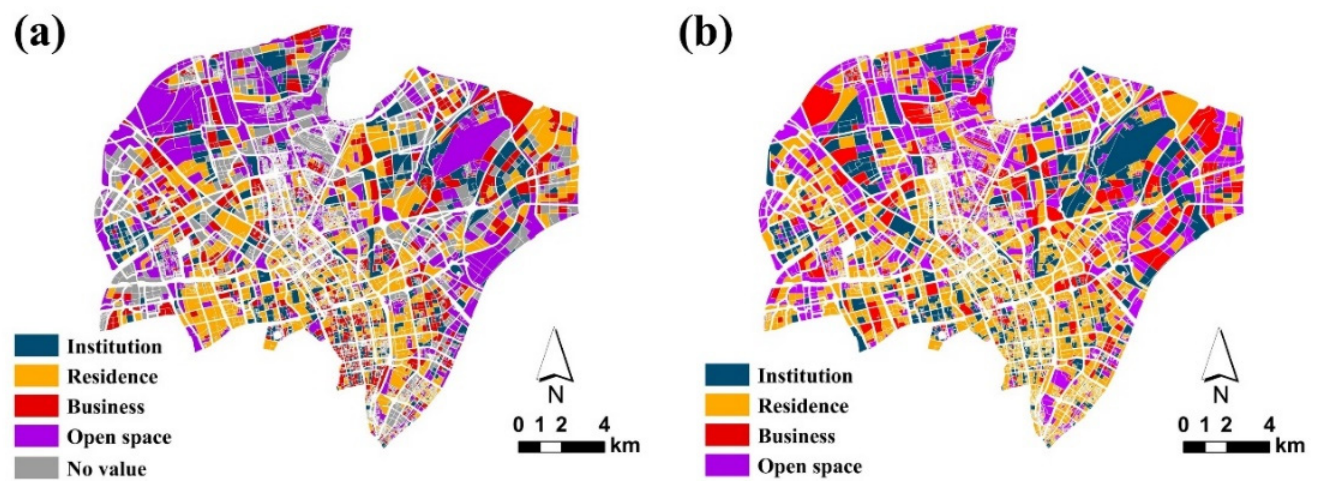

Figure 7. Illustration of the (a) DI-based and (b) FI-based urban land use maps in Hangzhou city.

Figure 8 presents a visual comparison of the urban land use maps derived from DIbased and FI-based methods and the corresponding Baidu map in four subareas. The four subareas A, B, C, and D are dominated by institution, residence, business and opens space, respectively. Overall, the visual comparison indicates a generally better performance of the DI-based classification than the FI-based classification. For example, some institution parcels were classified as residence for the FI-based classification in subarea A. In subarea $\mathrm{B}$, some residence parcels were misclassified as business by the FI-based classification. The FI-based result map misclassified business parcels as residence parcels in subarea C. For subarea D, the open space parcel was wrongly classified as a residence parcel. 


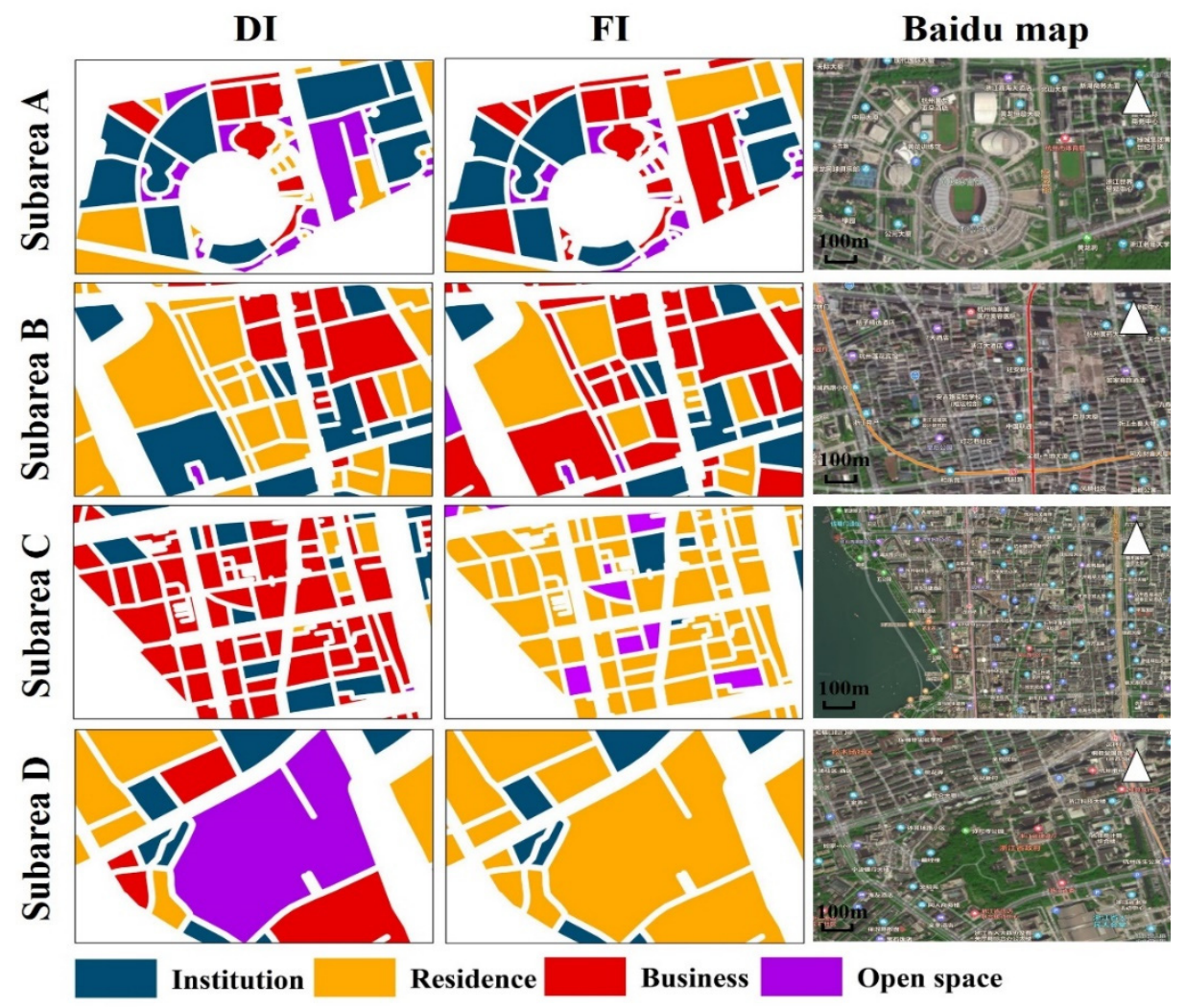

Figure 8. Classification results of DI and FI methods and testing samples in the test regions. Subareas A, B, C, and D were selected randomly in Hangzhou city, and each region was shown with DI-based classification, FI-based classification, and Baidu map. The Chinese labels for the subfigure of right column represent the name of POIs.

\section{Discussion}

This study implemented the DI-based and FI-based methods for mapping urban land use types in Hangzhou city, based on the same urban land use classification system (Table 1), the same data sources (i.e., Sentinel-2A, OSM road networks, and POI), and the same training and validation urban parcels (Figure 5). In our study, the only difference between these two approaches is the manner and timing for integrating the RS features and GBD features (Figures 1 and 3). It should be noted that the objective of this study is not to quantitatively compare the performance of the two methods but to illustrate their advantages and disadvantages by applying them to the mapping of the urban land use situation in Hangzhou city. The results in this study, which show that DI-based classification performs better than FI-based classification, may not apply to other circumstances [36,64]. Given that our study area is located in eastern China, where the diversity of urban land use types has a higher level of complexity than other regions in China, our mapping result is probably not representative of other regions. It should be noted that different data sources, selected features, classifiers, training samples, or land use types may also lead to different results. According to the process of the integration methods, these differences can be summarized into four types: (1) different urban road networks in different regions might lead to different urban parcel unit; (2) The variety of GBD in different regions lead to different mapping results; (3) The number of mixed parcels in different regions varies depending on the tiers of cities; (4) The availability of RS data greatly varies in different cities due to the coverage of clouds and cloud shadows that might be another factor affecting the application of the proposed methods. 


\subsection{Summary of the Advantages and Disadvantages of the Two Methods}

In our study, for the DI-based method, the pervious and impervious surfaces map was overlaid with urban parcels for generating built-up and non-built-up parcels, and then they were classified into the four urban land use types by calculating the frequency density and weight of the four types of POI. For the FI-based classification, the RS and GBD features were combined to train the RF model for urban land use mapping based on the training parcels. Some advantages and disadvantages could be identified through the analysis of classification results and the above-mentioned process:

- DI-based urban land use mapping is easy to implement, avoids feature integration, and accompanies conflicting issues. However, it depends largely on the quality and quantity of the GBD in each urban parcel (it depended on POI data in our case study) which might cause the missing value and misclassification for some urban parcels (Figures 7 and 8). For example, Zhao et al. [28] indicated that inaccurate POI will produce incorrect labels, as the classification results are directly generated from POI. Furthermore, the classes used in this paper might not match well with the POI classes considering that DI-based classification is based on labeling parcels based on POI. Reclassifying POI classes according to the nomenclature of land use types can result in some uncertainties of urban land use classification. For example, certain POI could be associated with more than one type of urban land use;

- The FI-based land use mapping enables the mixture of features from RS and GBD, however, the implementation has challenges due to the modality gap [20,32] between the RS and GBD, such as the spatial data quality, technical format, and data structure. Moreover, both feature selection and feature integration in the FI-based classification can contribute to different mapping results. In this study, spectral features and textural features derived from the Sentinel-2 image were integrated with the density features derived from POI for mapping urban land use (Table 3). Accordingly, these features have multiple backgrounds and thus can have various understandings of urban land use mapping, leading to different classification results [65]. The performance of the FI-based classification is probably related to the complexity of urban parcels. To be more specific, a single urban parcel can comprise different urban land uses, such as office buildings, residential buildings, and shopping centers. Therefore, the differences in features among urban parcels might be hard to distinguish.

\subsection{The Improved Method for Urban Land Use Mapping}

Given the framework (Figure 1), quantitative and qualitative assessments (Tables 5 and 6, Figures 7 and 8) of the two methods, it is possible to highlight some points for improving the DI-based and FI-based urban land use mapping. First, very-high-resolution (VHR) satellite images provide abundant information about geographical objects in terms of geometrical features and spatial patterns [28], which can provide more detailed RS information (e.g., textual, contextual, and spectral information) [37]. Second, the generation of urban parcels relied on the OSM road network, which contains unbalanced classes that are unevenly distributed, leading to heterogeneous urban land use parcels in terms of parcel area and spatial pattern [66]. The accuracy of the urban parcels created based on OSM can be further improved by combining different data sources, and the veracity of urban parcels should be validated. Third, different GBD features have different contributions to the classification of different land use types according to Zhang et al. [37]. Evaluating the optimal size of the GBD set is a topic for future research. Fourth, the training and testing parcels used in this study were identified through the Baidu map, Baidu street view, and a field survey, which are promising to validate urban land use parcels [67]. However, it is inevitable for parcels to contain multiple land use types. A better classification performance would be expected from the adoption of an independent land use map from the local government and urban planners [68]. Fifth, the RF model was used for mapping built-up in DI-based classification and training urban land use parcels in the FI-based classification. However, we need to improve the RF model with transfer learning capability for mapping 
the urban land use of any region with high accuracy and a different data source. To be more specific, the transfer learning model can be used as a pre-trained model, which might help increase the classification accuracy. Furthermore, how to integrate GBD into the RF model is a worthwhile question to discuss, since there is a significant difference between RS and GBD [39]. Sixth, the two methods can be used together to improve urban land use maps as they have different performances in classifying different types of land use. For example, the FI-based method can be used for classifying very different urban land use types, such as open space land and industrial land, while the DI-based method can be utilized for classifying urban land use types with very little difference in the RS features but have a significant difference in GBD features, such as commercial land and industrial land.

\section{Conclusions}

With the increase in RS and GBD, integrating the two types of data was widely used in urban land use mapping in recent years as it provides an opportunity to characterize both physical and socioeconomic attributes of urban land. For the first time, this study summarized the diverse methods of RS and GBD integration used in essential urban land use mapping and categorized them into two types, including the DI-based and FI-based methods. A general framework was proposed for explaining the main differences in the process of the two methods. Taking Hangzhou city, China as a case study, we then applied the two methods to produce the urban land use maps consisting of the institution, residence, business, and open space, based on the OSM road network, Sentinel-2 data, and Gaode POI, and highlighted the differences in classification results and the process of the DI-based and FI-based methods. On this basis, future studies should pay more attention to the integration methods, and further apply the methods to more specific classification-type scenarios, data sources, and other regions.

Supplementary Materials: The following are available online at https:/ /www.mdpi.com/article/10 $.3390 /$ rs13081579/s1, Table S1: Contingency table for accuracy assessment, Table S2: Contingency table for accuracy assessment in terms of proportion of numbers, Table S3: Contingency table for evaluating map accuracy of DI-based classification results (I: Institution; R: Residence; B: Business; O: Open Space), Table S4: Contingency table for evaluating map accuracy of FI-based classification results (I: Institution; R: Residence; B: Business; O: Open Space).

Author Contributions: J.Y. and N.A.S.H. conducted the data analysis and wrote the manuscript; J.Y., N.Y., and Y.H. developed the methodology; Z.L., P.F., N.A.S.H., A.C., and J.D. provided valuable insights and edited the manuscript. All authors have read and agreed to the published version of the manuscript.

Funding: This research was supported by the National Natural Science Foundation of China (Grant nos. 41971078, 41871349, 41801336). The Chinese Academy of Sciences the Strategic Priority Research Program (XDA19040301), the Key Research Program of Frontier Sciences (QYZDB-SSW-DQC005).

Acknowledgments: J.Y. acknowledges a Ph.D. scholarship provided by the University of Nottingham Ningbo China and the Institute for Geographic Sciences and Natural Resources Research, Chinese Academy of Sciences.

Conflicts of Interest: The authors declare no conflict of interest.

\section{References}

1. Gong, P.; Li, X.; Zhang, W. 40-Year (1978-2017) human settlement changes in China reflected by impervious surfaces from satellite remote sensing. Sci. Bull. 2019, 64, 756-763. [CrossRef]

2. Zhu, Z.; Zhou, Y.; Seto, K.C.; Stokes, E.C.; Deng, C.; Pickett, S.T.A.; Taubenböck, H. Understanding an urbanizing planet: Strategic directions for remote sensing. Remote Sens. Environ. 2019, 228, 164-182. [CrossRef]

3. Liu, X.; Hu, G.; Chen, Y.; Li, X.; Xu, X.; Li, S.; Pei, F.; Wang, S. High-resolution multi-temporal mapping of global urban land using Landsat images based on the Google Earth Engine Platform. Remote Sens. Environ. 2018, 209, 227-239. [CrossRef]

4. Reba, M.; Seto, K.C. A systematic review and assessment of algorithms to detect, characterize, and monitor urban land change. Remote Sens. Environ. 2020, 242, 111739. [CrossRef] 
5. Qi, L.; Li, J.; Wang, Y.; Gao, X. Urban observation: Integration of remote sensing and social media data. IEEE J. Select. Top. Appl. Earth Observat. Remote Sens. 2019, 1-13. [CrossRef]

6. Li, J.; He, Z.; Plaza, J.; Li, S.; Chen, J.; Wu, H.; Wang, Y.; Liu, Y. Social media: New perspectives to improve remote sensing for emergency response. Proc. IEEE 2017, 105, 1900-1912. [CrossRef]

7. Cai, J.; Huang, B.; Song, Y. Using multi-source geospatial big data to identify the structure of polycentric cities. Remote Sens. Environ. 2017, 202, 210-221. [CrossRef]

8. Kitchin, R.; McArdle, G. What makes Big Data, Big Data? Exploring the ontological characteristics of 26 datasets. Big Data Soc. 2016, 3, 205395171663113. [CrossRef]

9. Li, S.; Dragicevic, S.; Castro, F.A.; Sester, M.; Winter, S.; Coltekin, A.; Pettit, C.; Jiang, B.; Haworth, J.; Stein, A.; et al. Geospatial big data handling theory and methods: A review and research challenges. ISPRS J. Photogramm. Remote Sens. 2016, 115, 119-133. [CrossRef]

10. Ratti, C.; Frenchman, D.; Pulselli, R.M.; Williams, S. Mobile landscapes: Using location data from cell phones for urban analysis. Environ. Plann. B Plann. Des. 2016, 33, 727-748. [CrossRef]

11. Wu, L.; Cheng, X.; Kang, C.; Zhu, D.; Huang, Z.; Liu, Y. A framework for mixed-use decomposition based on temporal activity signatures extracted from big geo-data. Int. J. Digit. Earth 2020, 13, 708-726. [CrossRef]

12. Andrade, R.; Alves, A.; Bento, C. POI mining for land use classification: A case study. ISPRS Int. J. Geo-Inf. 2020, 9, 493. [CrossRef]

13. Ilieva, R.T.; McPhearson, T. Social-media data for urban sustainability. Nat. Sustain. 2018, 1, 553-565. [CrossRef]

14. Yammine, S.Z.; Jarreau, P.B.; Liu, C.; Coe, I.R. Social media for social change in science. Science 2018, $360,163$.

15. Ye, X.; Huang, Q.; Li, W. Integrating big social data, computing and modeling for spatial social science. Cartogr. Geogr. Inf. Sci. 2016, 43, 377-378. [CrossRef]

16. Niu, N.; Liu, X.; Jin, H.; Ye, X.; Liu, Y.; Li, X.; Chen, Y.; Li, S. Integrating multi-source big data to infer building functions. Int. J. Geogr. Inf. Sci. 2017, 31, 1871-1890. [CrossRef]

17. Srivastava, S.; Vargas Muñoz, J.E.; Lobry, S.; Tuia, D. Fine-grained landuse characterization using ground-based pictures: A deep learning solution based on globally available data. Int. J. Geogr. Inf. Sci. 2018, 34, 1117-1136. [CrossRef]

18. Krylov, V.; Kenny, E.; Dahyot, R. Automatic discovery and geotagging of objects from street view imagery. Remote Sens. 2018, 10, 661. [CrossRef]

19. Cadavid Restrepo, A.M.; Yang, Y.R.; Hamm, N.A.S.; Gray, D.J.; Barnes, T.S.; Williams, G.M.; Soares Magalhaes, R.J.; McManus, D.P.; Guo, D.; Clements, A.C.A. Land cover change during a period of extensive landscape restoration in Ningxia Hui Autonomous Region, China. Sci. Total Environ. 2017, 598, 669-679. [CrossRef]

20. Liu, Y.; Liu, X.; Gao, S.; Gong, L.; Kang, C.; Zhi, Y.; Chi, G.; Shi, L. Social sensing: A new approach to understanding our socioeconomic environments. Ann. Assoc. Am. Geogr. 2015, 105, 512-530. [CrossRef]

21. Li, J.; Benediktsson, J.A.; Zhang, B.; Yang, T.; Plaza, A. Spatial technology and social media in remote sensing: Challenges and opportunities. Proc. IEEE 2017, 105, 1583-1585. [CrossRef]

22. Sarmin, N.S.; Ismail, M.H. A review of potentialities and challenges of integrating remote sensing and GIS with socioeconomic data. PJSRR 2016, 2, 129-141.

23. Dong, J.; Metternicht, G.; Hostert, P.; Fensholt, R.; Chowdhury, R.R. Remote sensing and geospatial technologies in support of a normative land system science: Status and prospects. Curr. Opin. Environ. Sustain. 2019, 38, 44-52. [CrossRef]

24. Xiong, G.; Cao, X.; Hamm, N.A.S.; Lin, T.; Zhang, G.; Chen, B. Unbalanced development characteristics and driving mechanisms of regional urban spatial form: A case study of Jiangsu Province, China. Sustainability 2021, 13, 3121. [CrossRef]

25. Zhang, X.; Du, S.; Zheng, Z. Heuristic sample learning for complex urban scenes: Application to urban functional-zone mapping with VHR images and POI data. ISPRS J. Photogramm. Remote Sens. 2020, 161, 1-12. [CrossRef]

26. Goffi, A.; Bordogna, G.; Stroppiana, D.; Boschetti, M.; Brivio, P.A. Knowledge and data-driven mapping of environmental status indicators from remote sensing and VGI. Remote Sens. 2020, 12, 495. [CrossRef]

27. Zhang, Y.; Li, Q.; Tu, W.; Mai, K.; Yao, Y.; Chen, Y. Functional urban land use recognition integrating multi-source geospatial data and cross-correlations. Comput. Environ. Urban Syst. 2019, 78, 101374. [CrossRef]

28. Zhao, W.; Bo, Y.; Chen, J.; Tiede, D.; Blaschke, T.; Emery, W.J. Exploring semantic elements for urban scene recognition: Deep integration of high-resolution imagery and OpenStreetMap (OSM). ISPRS J. Photogramm. Remote Sens. 2019, 151, 237-250. [CrossRef]

29. Shi, Y.; Qi, Z.; Liu, X.; Niu, N.; Zhang, H. Urban land use and land cover classification using multisource remote sensing images and social media data. Remote Sens. 2019, 11, 2719. [CrossRef]

30. Liu, X.; He, J.; Yao, Y.; Zhang, J.; Liang, H.; Wang, H.; Hong, Y. Classifying urban land use by integrating remote sensing and social media data. Int. J. Geogr. Inf. Sci. 2017, 31, 1675-1696. [CrossRef]

31. Jia, Y.; Ge, Y.; Ling, F.; Guo, X.; Wang, J.; Wang, L.; Chen, Y.; Li, X. Urban land use mapping by combining remote sensing imagery and mobile phone positioning data. Remote Sens. 2018, 10, 446. [CrossRef]

32. Cao, R.; Tu, W.; Yang, C.; Li, Q.; Qiu, G. Deep learning-based remote and social sensing data fusion for urban region function recognition. ISPRS J. Photogramm. Remote Sens. 2020, 163, 82-97. [CrossRef]

33. Chang, C.; Ye, Z.; Huang, Q.; Wang, C. An integrative method for mapping urban land use change using "geo-sensor" data. In Proceedings of the 1st International ACM SIGSPATIAL Workshop on Smart Cities and Urban Analytics, UrbanGIS'15, Bellevue, WA, USA, 3-6 November 2015; pp. 47-54. 
34. Song, J.; Lin, T.; Li, X.; Prishchepov, A.V. Mapping urban functional zones by integrating very high spatial resolution remote sensing imagery and points of interest: A case study of Xiamen, China. Remote Sens. 2018, 10, 1737. [CrossRef]

35. Tu, W.; Hu, Z.; Li, L.; Cao, J.; Jiang, J.; Li, Q.; Li, Q. Portraying urban functional zones by coupling remote sensing imagery and human sensing data. Remote Sens. 2018, 10, 141. [CrossRef]

36. Xu, S.; Qing, L.; Han, L.; Liu, M.; Peng, Y.; Shen, L. A new remote sensing images and point-of-interest fused (RPF) model for sensing urban functional regions. Remote Sens. 2020, 12, 1032. [CrossRef]

37. Zhang, Y.; Li, Q.; Huang, H.; Wu, W.; Du, X.; Wang, H. The combined use of remote sensing and social sensing data in fine-grained urban land use mapping: A case study in Beijing, China. Remote Sens. 2017, 9, 865. [CrossRef]

38. Li, D.; Lu, D.; Wu, M.; Shao, X.; Wei, J. Examining land cover and greenness dynamics in Hangzhou bay in 1985-2016 using Landsat time-series data. Remote Sens. 2017, 10, 32. [CrossRef]

39. Mao, W.; Lu, D.; Hou, L.; Liu, X.; Yue, W. Comparison of machine-learning methods for urban land-use mapping in Hangzhou City, China. Remote Sens. 2020, 12, 2817. [CrossRef]

40. Drusch, M.; Del Bello, U.; Carlier, S.; Colin, O.; Fernandez, V.; Gascon, F.; Hoersch, B.; Isola, C.; Laberinti, P.; Martimort, P.; et al. Sentinel-2: ESA's optical high-resolution mission for GMES operational services. Remote Sens. Environ. 2012, 120, 25-36. [CrossRef]

41. Zhu, Z.; Wang, S.; Woodcock, C.E. Improvement and expansion of the Fmask algorithm: Cloud, cloud shadow, and snow detection for Landsats 4-7, 8, and Sentinel 2 images. Remote Sens. Environ. 2015, 159, 269-277. [CrossRef]

42. Adiri, Z.; Lhissou, R.; El Harti, A.; Jellouli, A.; Chakouri, M. Recent advances in the use of public domain satellite imagery for mineral exploration: A review of Landsat-8 and Sentinel-2 applications. Ore Geol. Rev. 2020, 117, 103332. [CrossRef]

43. Weiss, D.J.; Nelson, A.; Gibson, H.S.; Temperley, W.; Peedell, S.; Lieber, A.; Hancher, M.; Poyart, E.; Belchior, S.; Fullman, N.; et al. A global map of travel time to cities to assess inequalities in accessibility in 2015. Nature 2018, 553, 333-336. [CrossRef] [PubMed]

44. Helbich, M.; Amelunxen, C.; Neis, P.; Zipf, A. Comparative spatial analysis of positional accuracy of OpenStreetMap and proprietary Geodata. In Proceedings of the GI_Forum 2012: Geovisualization, Society and Learning, Salzburg, Austria, 3-6 July 2012; pp. 4-6.

45. Liu, D.; Chen, N.; Zhang, X.; Wang, C.; Du, W. Annual large-scale urban land mapping based on Landsat time series in Google Earth Engine and OpenStreetMap data: A case study in the middle Yangtze River basin. ISPRS J. Photogramm. Remote Sens. 2020, 159, 337-351. [CrossRef]

46. Wan, T.; Lu, H.; Lu, Q.; Luo, N. Classification of high-resolution remote-sensing image using OpenStreetMap information. IEEE Geosci. Remote Sens. Lett. 2017, 14, 2305-2309. [CrossRef]

47. Liu, X.; Long, Y. Automated identification and characterization of parcels with OpenStreetMap and points of interest. Environ. Plann. B 2015, 43, 498-510. [CrossRef]

48. Rozenfeld, H.D.; Rybski, D.; Gabaix, X.; Makse, H.A. The area and population of cities: New insights from a different perspective on cities. Am. Econ. Rev. 2011, 101, 2205-2225. [CrossRef]

49. Ministry of Housing and Urban-Rural Development (MoHURD). Code for Design of Urban Road Engineering CJJ37; China Architecture \& Building Press: Beijing, China, 2012.

50. Kang, J.; Körner, M.; Wang, Y.; Taubenböck, H.; Zhu, X.X. Building instance classification using street view images. ISPRS J. Photogramm. Remote Sens. 2018, 145, 44-59. [CrossRef]

51. Hoffmann, E.J.; Wang, Y.; Werner, M.; Kang, J.; Zhu, X.X. Model fusion for building type classification from aerial and street view images. Remote Sens. 2019, 11, 1259. [CrossRef]

52. Gong, P.; Chen, B.; Li, X.; Liu, H.; Wang, J.; Bai, Y.; Chen, J.; Chen, X.; Fang, L.; Feng, S.; et al. Mapping essential urban land use categories in China (EULUC-China): Preliminary results for 2018. Sci. Bull. 2020, 65, 182-187. [CrossRef]

53. Stehman, S.V.; Foody, G.M. Key issues in rigorous accuracy assessment of land cover products. Remote Sens. Environ. 2019, 231, 111199. [CrossRef]

54. Weng, Q. Remote sensing of impervious surfaces in the urban areas: Requirements, methods, and trends. Remote Sens. Environ. 2012, 117, 34-49. [CrossRef]

55. Zhao, W.; Li, Q.; Li, B. Extracting hierarchical landmarks from urban POI data. J. Remote Sens. 2011, 15, $973-988$.

56. Puissant, A.; Hirsch, J.; Weber, C. The utility of texture analysis to improve per-pixel classification for high to very high spatial resolution imagery. Int. J. Remote Sens. 2006, 26, 733-745. [CrossRef]

57. Lu, D.; Weng, Q. Use of impervious surface in urban land-use classification. Remote Sens. Environ. 2006, 102, 146-160. [CrossRef]

58. Carlson, T.N.; Ripley, D.A. On the relation between NDVI, fractional vegetation cover, and leaf area index. Remote Sens. Environ. 1997, 62, 241-252. [CrossRef]

59. Heiden, U.; Segl, K.; Roessner, S.; Kaufmann, H. Determination of robust spectral features for identification of urban surface materials in hyperspectral remote sensing data. Remote Sens. Environ. 2007, 111, 537-552. [CrossRef]

60. Deng, J.; Huang, Y.; Chen, B.; Tong, C.; Liu, P.; Wang, H.; Hong, Y. A methodology to monitor urban expansion and green space change using a time series of multi-sensor SPOT and sentinel-2A images. Remote Sens. 2019, 11, 1230. [CrossRef]

61. Foody, G.M. Status of land cover classification accuracy assessment. Remote Sens. Environ. 2002, 80, 185-201. [CrossRef]

62. Card, D.H. Using known map category marginal frequencies to improve estimates of thematic map accuracy. Photogramm. Eng. Remote Sens. 1982, 48, 431-439. 
63. Olofsson, P.; Foody, G.M.; Herold, M.; Stehman, S.V.; Woodcock, C.E.; Wulder, M.A. Good practices for estimating area and assessing accuracy of land change. Remote Sens. Environ. 2014, 148, 42-57. [CrossRef]

64. Yu, B.; Lian, T.; Huang, Y.; Yao, S.; Ye, X.; Chen, Z.; Yang, C.; Wu, J. Integration of nighttime light remote sensing images and taxi GPS tracking data for population surface enhancement. Int. J. Geogr. Inf. Sci. 2019, 33, 687-706. [CrossRef]

65. Su, M.; Guo, R.; Chen, B.; Hong, W.; Wang, J.; Feng, Y.; Xu, B. Sampling strategy for detailed urban land use classification: A systematic analysis in Shenzhen. Remote Sens. 2020, 12, 1497. [CrossRef]

66. Johnson, B.A.; Iizuka, K. Integrating OpenStreetMap crowdsourced data and Landsat time-series imagery for rapid land use/land cover (LULC) mapping: Case study of the Laguna de Bay area of the Philippines. Appl. Geogr. 2016, 67, 140-149. [CrossRef]

67. Hu, T.; Yang, J.; Li, X.; Gong, P. Mapping urban land use by using Landsat images and open social data. Remote Sens. $2016,8,151$. [CrossRef]

68. Pan, H.; Tong, X.; Xu, X.; Luo, X.; Jin, Y.; Xie, H.; Li, B. Updating of land cover maps and change analysis using GlobeLand30 product: A case study in Shanghai metropolitan area, China. Remote Sens. 2020, 12, 3147. [CrossRef] 